\title{
Representações sociais e instituição da realidade no subcampo esportivo do montanhismo: uma possibilidade de leitura sociológica a partir da obra "Sobre homens e montanhas" de J on Krakauer
}

\author{
J uliano de SOUZA* \\ Renata Maria TOLEDO* \\ *Universidade Federal \\ do Paraná \\ Wanderley MARCHI J UNIOR*
}

\begin{abstract}
Resumo
Os objetivos nos quais se pautou a construção do presente artigo conduzem, de um lado, a identificar algumas representações sociais presentes no universo do montanhismo e, de outro, entender a forma como essas mesmas representações, em meio à luta e à concorrência, contribuem para a construção da realidade social nesse universo empirico delimitado. Para o desenvolvimento dessa proposta buscou-se suporte teórico-metodológico na sociologia reflexiva de Pierre Bourdieu, sobretudo em sua forma adquirida e explicitada na construção da teoria das representações sociais, da economia dos bens simbólicos e dos lucros de distinção no campo esportivo. Por fim, substanciou-se ainda nas considerações empíricas tecidas pelo alpinista e escritor Jon Krakauer em seu best-seller "Sobre homens e montanhas".
\end{abstract}

UnIteRmos: Representações sociais; Montanhismo; Sociologia; Pierre Bourdieu.

\section{Introdução}

Antes marginal, o esporte progressivamente se consolida como um objeto digno de estudo no campo das Ciências Sociais. Tal movimento não se desencadeou isolada e repentinamente, sendo, pelo contrário, um dos reflexos da importância e capilaridade que o fenômeno esportivo vem conquistando na sociedade.

Cabe aqui ressaltar que não apenas o esporte adquiriu uma modificação de seu "status" como objeto de estudo das Ciências Sociais, mas as próprias teorias que foram produzidas no interior dessa área de conhecimento passaram a apresentar um maior alcance como referenciais teórico-metodológicos no campo acadêmico da Educação Física, disciplina na qual o esporte histórica e predominantemente veio a se vincular.

No âmbito desse prognóstico sumariado é possível ainda notar um progressivo interesse dos pesquisadores em estudar os esportes realizados em contato com a natureza, fator esse que, em última análise, acompanha o crescimento que essas modalidades vêm alcançando dentre as demais práticas esportivas na sociedade. É na esteira, portanto, dessas investigaçóes acerca dos esportes da natureza que se situa o presente texto, no qual se propõe uma leitura sociológica do montanhismo com base em alguns constructos teórico-metodológicos do sociólogo francês Pierre Bourdieu.

Deste modo, este artigo tem por objetivo identificar, de um lado, algumas das representações sociais que se apresentaram simbolicamente no universo do montanhismo e, de outro, a entender a forma como essas mesmas representaçôes, em meio à luta e à concorrência, contribuíram para a construção da realidade social nesse universo delimitado.

Para o desenvolvimento dessa proposta, primeiramente, procura-se apresentar e introduzir o leitor, de forma sucinta, à teoria das representações sociais de Pierre Bourdieu. Em seguida, a abordagem é direcionada para economia dos bens simbólicos e dos lucros 
de distinção materializados no campo esportivo. Por fim, é efetuada uma análise, a partir das considerações empíricas tecidas pelo alpinista e escritor Jon Krakauer no livro "Sobre homens e montanhas", a respeito de algumas das formas com que as representações são apropriadas e reproduzidas pelos agentes no intuito, não necessariamente calculista e racional, de instituir a realidade social no subcampo esportivo em questão.

\section{A teoria das representações sociais de Pierre Bourdieu}

"A ciência social precisa examinar a parte que cabe às palavras na construção das coisas sociais" (BOURDIEU, 1998, p.81). De modo sintético, essa é uma das mais significativas sistematizações da sociologia de Pierre Bourdieu no que se refere à importância em se estudar a forma com que as representações norteiam as disposiçôes dos agentes e organizam as práticas sociais. $\mathrm{Na}$ esteira dessa análise, o autor francês, rigorosa e insistentemente, reivindica e demonstra a urgência em examinar-se a forma ou as formas pelas quais a ordem das palavras, ou seja, das representações sociais, contribuem para a instituição da ordem das práticas sociais.

Inicialmente, é importante lembrar que a teoria das representações de Bourdieu foi circunscrita na continuidade e prolongamento dos trabalhos de Émile Durkheim, ou seja, como formas de classificação social. $\mathrm{O}$ avanço em relação ao último, entretanto, é que além de se ater à gênese das classificações sociais, Bourdieu procurou aperfeiçoar o estudo da relação mantida pelas mesmas classificações com as divisōes sociais sem desconsiderar a centralidade da ação prática dos agentes, ou, mais precisamente, identificar o papel das classificaçóes na construção estruturada e estruturante da realidade.

Essas impressões são mais bem situadas na fala dos próprios sociólogos. DURKHEIM (1996, p.19) adverte que, "só se pode definir o rito após se ter definido a crença”. BOURDIEU (1998, p.105), por sua vez, lembra que, "a crença de todos, preexistente ao ritual, é a condição de eficácia do ritual”. Desse modo, enquanto Durkheim privilegia o estudo das representações como parte inerente e constitutiva das dinâmicas próprias aquilo que chamou de fatos sociais, Bourdieu recupera o papel dos agentes diante das representaçôes e da subsequente construção da realidade.

Para Bourdieu, portanto, as representaçôes sociais constituem-se simultaneamente como uma realidade objetivada e objetivante. E isso basicamente porque as representações práticas podem contribuir para produzir o que aparentemente elas descrevem ou designam. Logo, como "enunciados performativos que pretender fazer acontecer o que eles enunciam", (BOURDIEU, 1998, p.112), as representaçôes se tratam, de lutas pelas classificações, isto é, “(...) lutas pelo monopólio do poder de fazer ver e fazer crer, de fazer conhecer e de fazer reconhecer, de impor uma definição legítima das divisões do mundo social e, por essa via, de fazer e desfazer os grupos" (Bourdieu, 1998, p.108).

Desta maneira, as divisóes do mundo social são encaradas por Bourdieu como classificações, ou melhor, lutas objetivas em torno da definição legítima das diferentes identidades sociais. Além disso, essas lutas pelas representaçôes materializadas no interior de determinado campo estruturam, em última instância, o próprio campo de tensões em que são vinculadas, bem como, as demais práticas sociais que nele se engendram. Dito de outro modo, "quando as representações oficiais daquilo que um homem é oficialmente em um espaço social dado tornam-se habitus, elas se tornam o fundamento real das práticas" (Bourdieu, 2007b, p.152).

Outro ponto a ser recuperado dessa análise, é que as representações conforme trabalhadas na sociologia bourdieusiana estão fundadas nas estratégias de conhecimento, reconhecimento e desconhecimento. As duas primeiras são aquelas que alicerçam as relaçôes sociais viabilizadas entre os agentes num referido campo e, reservam a particularidade, de assegurar a reprodução das estruturas sociais em determinado intervalo de tempo-espaço.

A terceira estratégia é mais velada, consistindo no fato de um agente se apresentar ingênuo ao funcionamento do jogo ou então quando ele se esquece de si mesmo, contribuindo para a instituição de fundamentos simbólicos e perversos de dominação de que ele próprio se torna vítima. Nas palavras do próprio Bourdieu:

$\mathrm{O}$ ato da magia social de tentar dar a existência à coisa nomeada será bem-sucedido quando aquele que o efetua for capaz de fazer reconhecer por sua palavra o poder que tal palavra garante por uma usurpação provisória ou definitiva, qual seja o poder de impor uma nova visão e uma nova divisão do mundo social: regere fines, regere sacra, consagrar um novo limite. A eficácia do discurso performativo que pretende fazer acontecer o 
que enuncia no próprio ato de enunciá-lo é proporcional à autoridade daquele que o enuncia: a fórmula "eu o autorizo a partir" constitui eo ipso uma autorização quando aquele que a pronuncia está autorizado a autorizar, tem autoridade para autorizar (Bourdieu, 1998, p.111).

Desse modo, tal como retomadas e repensadas na sociologia de Pierre Bourdieu, as representações apropriadas por um porta-voz legítimo -, são também entendidas como atos de nomeação, classificação e categorização, que contribuem de forma velada, e quanto menos os agentes tenham consciência disso, para fundar e manter o funcionamento interno dos mais diversos grupos, bem como as dinâmicas das relações sociais. Essa retomada, por conseguinte, consiste em "considerar os esquemas geradores dos sistemas de classificação e de percepção como verdadeiras instituiçôes sociais, incorporando sob a forma de representaçóes coletivas as divisóes da organização social" (CHARTIER, 2002, p.72).

Por conta dessa leitura é importante ressaltar ainda que para que as representaçóes constituam efetivamente a realidade de determinado campo necessitam, conforme ensaiamos acima, de um porta-voz, o qual na medida em que pretende trazer a ordem material àquilo que enuncia, atrai certas vantagens simbólicas à sua posição e vice-versa. Entretanto, para eficácia de tal estratégia requer-se a cumplicidade dos demais agentes envolvidos, instituindo uma verdadeira,

(...) alquimia da representação (...) através da qual o representante constitui o grupo que o constitui: o porta-voz dotado do poder pleno de falar e de agir em nome do grupo, falando sobre o grupo pela magia da palavra da ordem, é o substituto do grupo que existe somente por esta procuração (BouRdieu, 1998, p.83).

Em última análise, é possível afirmar então que existe um princípio de contribuição dada à construção do real pela representação que os agentes têm do real. Entretanto, para isso é necessário que existam agentes classificados, percebidos como distintos, e que em função dos lucros de distinção que determinadas práticas conferem e proporcionam, acabam entrando no jogo - luta mais ou menos travada para impor uma nova visão e di-visão das fronteiras e, por conseguinte, do mundo social.

Uma vez identificados alguns dos principais aspectos da teoria das representaçôes sociais na sociologia reflexiva de Bourdieu, e procurando estendê-los para análise do universo que constitui e contempla o conjunto de práticas esportivas estruturadas na sociedade, procura-se agora discorrer sobre a economia dos bens simbólicos e dos lucros de distinção, que sustentam as lutas no campo esportivo.

\section{A economia dos bens simbólicos e dos lucros de distinção no campo esportivo}

Uma das principais contribuiçōes tecidas por Bourdieu no conjunto de textos em que ele se propôs fundamentar uma economia cultural dos bens esportivos (Bourdieu, 1983b, 1990) é a estruturação de um quadro de análise que permite compreender devidamente a distribuição e orientação dos consumos e das práticas esportivas na sociedade. Para isso, o autor sistematiza basicamente uma economia cultural dos bens esportivos pautada na relação entre, de um lado, a oferta - bens esportivos oferecido aos agentes sob a forma de práticas e consumos - e de outro, a demanda - orientada pelo gosto e pelas transformações nos estilos de vida.

Ao pensar nas formas como se apresentam os consumos e as práticas esportivas, Bourdieu procura estabelecer relação reflexiva com as posições sociais. Segundo o sociólogo, na medida em que se desce na hierarquia social, a probabilidade de um agente praticar esporte depois da adolescência diminui nitidamente. Quanto à possibilidade de assistir aos espetáculos esportivos mais populares, essa decresce na medida em que os agentes sobem na hierarquia social (Bourdieu, 1983b, p.143). Conforme Bourdieu: Os lucros distintivos são dobrados quando a distinção entre as práticas distintas e distintivas, como os esportes "chiques", e as práticas que se tornaram "vulgares", devido à divulgação de vários esportes originalmente reservados à "elite", como o futebol (...) é acrescida da oposição, mais marcada ainda, entre a prática do esporte e o simples consumo de espetáculos esportivos (Bourdieu, 1983b, p.143).

Pode-se então perceber a formação de um campo esportivo substanciado pela tônica da dicotomia entre esporte-prática e esporte-espetáculo; entre esporte de elite e esporte de massa. Contudo, outras oposições também se vinculam a este campo, como as que seguem reiteradas: amadorismo contra o profissionalismo; esporte de lazer versus esporte de competição; esportes de contato direto e esportes à 
distância; esportes que requerem de maior atividade intelectual e menor dispêndio físico versus esportes que solicitam de maior uso da força e de uma menor capacidade de reflexão, e os exemplos se multiplicam.

Decorre desses sistemas de classificação e dicotomias, que o esporte em si confere um estilo de vida distintivo aos consumidores e praticantes. Dito de outro modo, o esporte moderno na forma como é consumido e praticado se demonstra perfeitamente compatível e complacente com a lógica de organização do espaço social, ou melhor, na condição de um campo onde estão em jogo às próprias definições legítimas da prática esportiva e dos usos diferenciados que se pode fazer do corpo nos esportes.

Aliás, é nesse mesmo espaço social que se definem o gosto dos agentes, através de uma alquimia das classificações imanente ao jogo, e que muito mais que indicar que "o motor de todas as condutas humanas seria a busca da distinção" (BOURDIEU, 2007b, p.22-3), demonstra que existir em um espaço é diferir; é ser diferente; é ser classificado e, ao mesmo tempo, classificante. Dessa forma, é perfeitamente compreensível que para haver gostos,

(...) é preciso que haja bens classificados, de

"bom" ou "mau" gosto, "distintos" ou "vulgares", classificados e ao mesmo tempo classificantes, hierarquizados e hierarquizantes, e que haja pessoas dotadas de princípios de classificações, de gostos, que Ihes permitam perceber entre estes bens aqueles que Ihes convém, aqueles que são "do seu gosto" (Bourdieu, 1983a, p.127).

Essa capacidade de percepção, apreciação, enfim, de escolhas de práticas, equivale a ter o sentido do jogo - "habitus" - impresso, tatuado no corpo, ou seja, incorporado nas formas de determinado agente, agir, encarar e se situar no espaço social. O gosto então enquanto conjunto de práticas e de propriedades de uma pessoa ou grupo funciona como "(...) operador prático da transmutação das coisas em sinais distintos e distintivos (...)" (Bourdieu, 2007a, p.166), possibilitando que as diferenças de ordem material se convertam em diferenças de ordem simbólica e vice-versa.

A partir de tais constataçôes, pode-se considerar o gosto como sendo o produto do encontro de duas histórias - uma objetivada e outra incorporada. História objetivada, pois se relaciona à exposição de bens e práticas nos campos de produção cultural, bem como a exteriorização da oferta, segundo sanções de uma economia não econômica que apresenta objetos e produtos propriamente classificados. E incorporada porque se interiorizam nos agentes os sistemas de classificação que lhes permitem escolher, dentro dos limites impostos pela estrutura e de maneira não consciente entre os bens e práticas disponíveis e precedentes ao gosto em si.

O esporte é uma dessas práticas classificadas, classificantes e classificadoras. Não obstante, os próprios serviços e bens de consumo relacionados à indústria do esporte também o são, definindo posições distintivas a serem antecipadas por agentes que possuem o senso do jogo requisitado. $E$ isso essencialmente porque esporte se trata de uma prática objetivamente classificada e com potencialidade a se converter em prática classificadora, isto é, a se tornar um lucro e expressão simbólica da distinção social.

Deste modo, não seria equivocado dizer que as diferentes posiçōes ocupadas pelos agentes no espaço social correspondem a estilos de vida mais ou menos ajustados, e, além disso, que os gostos de classe são a consequente incorporação da estrutura do espaço social através da formação do "habitus" desses mesmos agentes em uma região determinada do referido espaço.

$\mathrm{Na}$ definição dos estilos de vida, ou melhor, na "estilização da vida" é que residem, portanto, as variaçōes que balizam os gostos. Por sua vez, o gosto pode se exprimir de duas formas complementares, ou seja, contemplando as exigências impostas pela necessidade dos agentes e grupos, ou então, como estratégia cuja expectativa é suprir um estilo de vida distintivo e condizente com as posições ocupadas. Dessas impressōes, sucessivamente, derivam dois conceitos chaves desenvolvidos por BouRDIEU no livro "A distinção" (2007a): consumo cultural distinto e consumo cultural vulgar.

No primeiro caso, o consumo é entendido exatamente pela raridade e distinção social que engendra. Já no segundo caso, a banalidade e o fácil acesso ao produto, bem ou prática, representa o código de vulgaridade investido no jogo. Assim, o consumo distinto pressupõe um acúmulo razoável de capital econômico e cultural, ao passo que o consumo vulgar, geralmente, está desprovido do volume desses capitais.

No entanto, seria equivocado pensar o funcionamento desses pólos de maneira mecânica e determinista, o que, consequentemente, camuflaria a existência de uma posição intermediária. Para Bourdieu esse projeto não é válido, já que entre o consumo distinto e vulgar existem zonas intermediárias povoadas por práticas pretensiosas e pela discordância dos agentes (BOURDIEU, 2007a, p.167).

Desenvolvidas essas incursões teóricas, convém, neste momento, avançar à análise de alguns fragmentos pertinentes à construção da realidade e das práticas sociais no subcampo do montanhismo, a partir da fala e das impressões do montanhista e jornalista Jon Krakauer. 


\section{Representações sociais e instituição da realidade no universo do montanhismo}

O universo do montanhismo corresponde a um subcampo do campo esportivo, ou seja, a um subespaço inserido no espaço social mais amplo das práticas esportivas - universo social de análise delimitado na sociologia reflexiva de Bourdieu e que reserva a particularidade de ser um "locus" onde se travam lutas, mais ou menos, ajustadas em função de objetos específicos de disputa constituídos segundo as contingências históricas e estruturais de determinado momento.

Por sua vez, essa assertiva não se trata de um constructo arbitrário, mas de uma consideração teóricoprática corroborada tanto pelos fundamentos da sociologia reflexiva de Bourdieu quanto pela fala dos agentes inseridos na prática do montanhismo. Observe-se, por exemplo, o comentário do montanhista e jornalista Jon Krakauer:

O que leva alguém a escalar montanhas é algo que a maioria dos que não fazem parte do mundo dos montanhistas tem muita dificuldade para entender se é que entende. $\mathrm{O}$ tema se presta às mil maravilhas para filmes ruins e metáforas banais. Sonhar que se escala um pico altíssimo e escarpado é um prato feito para os psicanalistas. A atividade costuma vir associada a histórias de audácia e tragédia que tornam os outros esportes, por comparação, verdadeiros jogos de criança; quando falamos em montanhismo, a impressão que isso causa na imaginação do público não é muito diferente de quando ele ouve falar em tubaróes ou abelhas assassinas [Sic!] (KraKaUer, 1999, p.9).

Essas impressōes, de certa forma, possibilitam recuperar alguns dos pressupostos desenvolvidos por Bourdieu nos trabalhos no qual ele se ateve à análise dos consumos e práticas esportivas. No texto "Programa para uma sociologia do esporte" (1990), Bourdieu chama atenção para o fato de que um pesquisador não podendo estudar o espaço das práticas esportivas como um todo, deveria recortar um subespaço dentro desse espaço, isto é, delimitar um subcampo a fim de desenvolver sua respectiva análise.

Outro ponto essencial consiste em relacionar esse subcampo evidenciado aos demais subespaços que constituem o campo esportivo, para então reconhecer a posição que ele ocupa na referida estrutura. Por fim, e instaurando uma dialética entre estruturas micro e macrossociológicas, outro aspecto metodológico de singular importância seria identificar o espaço das posições sociais manifestos nos subcampos e no campo esportivo em sua totalidade.
Em diálogo com essa matriz teórica, o montanhismo pode ser entendido, portanto, como um subespaço no espaço das práticas esportivas; enfim, um subcampo que só pode ser compreendido a fundo a partir do momento em que se reconhece a posição que ele ocupa em relação aos demais esportes e quando, finalmente, se correlaciona o mesmo com o espaço das posições sociais que se manifestam nele e no próprio campo em que está previamente inserido.

Dessa maneira, sendo o montanhismo um subespaço desse "locus" específico de produção cultural, que envolve a luta pelas definições do modo legítimo de acessar as práticas esportivas, que é o campo esportivo, tal como Pierre Bourdieu formula em sua teoria sociológica, foi possível encontrar em seu universo simbólico, evidenciado aqui na fala de Krakauer, não apenas a luta pela distinção em relação a outras modalidades esportivas, classificadas por ele como "verdadeiros jogos de criança", como também a construção de uma representação distintiva para aqueles que se consagram às práticas vinculadas ao referido universo, ao associá-lo a elementos inacessíveis à vida cotidiana, como "tubarôes e abelhas assassinas".

No que diz respeito às palavras de Krakauer, convém ainda frisar a existência e circulação de habitus correspondentes e correlacionais à realidade vivenciada pelos agentes no universo esportivo em voga, o que, de antemão, pressupõe algumas condições de entrada para os referidos agentes no jogo "historicamente jogado" no interior do aludido subcampo. Sobre essas nuanças Bourdieu é enfático:

Ter o sentido do jogo é ter o jogo na pele; é perceber no estado prático o futuro do jogo, é ter o senso histórico do jogo. Enquanto o mau jogador está sempre fora do tempo, sempre muito adiantando ou muito atrasado, o bom jogador é aquele que antecipa que está adiante do jogo. Como ele pode antecipar o decorrer do jogo? Ele tem as tendências imanentes ao jogo no corpo, incorporadas: ele se incorpora ao jogo (BouRDIEU, 2007b, p.144).

No que se refere ao montanhismo, essa situação mencionada também assegura aos agentes a relativa posse de um capital específico inerente àquela realidade e que, por sinal, acaba se constituindo como umas das condiçôes de entrada no "jogo" e, além disso, o móvel das lutas aí engendradas. Por sua vez, essas lutas se apresentam objetivadas no subcampo e se fundam ora em relaçóes simbólicas, ora em relaçôes materiais, lembrando que para Bourdieu 
tal separação, conforme foi visto anteriormente, não é possível já que tanto as estratégias simbólicas fundam estratégias materiais e vice-versa.

Um bom exemplo desse argumento pode ser apreciado em relação ao próprio campo esportivo. Quando Bourdieu diz que o campo esportivo é um espaço de lutas e, dentre outras coisas, não simplesmente pelos usos que se pode fazer do corpo nas práticas esportivas, mas antes, pelas definiçôes legítimas dos usos do corpo no esporte, ele está considerando o papel que as representações conferem à construção da realidade, isto é, às lutas pelas classificações que estruturam o "jogo" a ser "jogado" no campo esportivo.

Outra possibilidade de discussão a ser aberta a partir fala de Krakauer há pouco enunciada, diz respeito à inserção de produtores culturais dos mais diversos campos no subcampo do montanhismo, ou então, de forma mais precisa, a apropriação que esses agentes exteriores ao universo do montanhismo, fazem dessa prática esportiva em seus respectivos campos de atuação.

O próprio livro "Sobre homens e montanhas", do qual se extraiu alguns fragmentos empíricos para subsidiar a presente análise, se trata de uma produção que, primeiramente foi publicada na forma de artigos para jornais de produção nacional norte-americana e, em seguida, para revista "Outside" - especializada em esportes de contato com a natureza. Trata-se, portanto, de uma apropriação específica do montanhismo no campo jornalístico, embora seja importante considerar o imperativo de que Krakauer conserva a particularidade de ser um agente que se movimenta em ambos os espaços, isto é, traz incorporado tanto o "sentido do jogo" do montanhismo quanto o "sentido do jogo" jornalístico, na sua forma de agir e encarar o mundo social.

Dando prosseguimento à discussão, convém, neste momento, se ater e se direcionar mais especificamente para estrutura narrativa presente no texto "Uma montanha mais alta que o Everest?" - capítulo integrante da obra em estudo. Nessa investida, procura-se localizar algumas representações sociais inerentes ao montanhismo e inferir de que forma essas representaçōes contribuíram para construção e tomada de posições nesse próprio universo que constitui a história estrutural relativamente autônoma da referida prática cultural e esportiva.

No capítulo "Uma montanha mais alta que o Everest?”, Krakauer procura recuperar algumas das disputas envolvidas na descoberta científica da montanha mais alta do mundo. Sua leitura é sugestiva e fornece alguns apontamentos para entender estratégias e disputas envoltas na história do montanhismo por um período de aproximadamente 150 anos.

Embora o relato se desenvolva de maneira contínua, como opção metodológica para essa exposição, elegeuse quatro pontos centrais do texto, que serão explorados a seguir: 1) relato sobre a descoberta e o "batismo" do Monte Everest; 2) os empreendimentos científicos para suplantar a referida descoberta; 3) apresentação e explicação dos procedimentos científicos necessários à aferição da altitude de uma montanha; e 4) possíveis desdobramentos da superação da altitude do Monte Everest por outra montanha, denominada K2.

Com relação à descoberta da montanha mais alta do mundo, o autor relata:

Numa tarde quente de 1852, conta a lenda, que o supervisor-geral do Grande levantamento Trigonométrico da Índia, Sir Andrew Waugh, estava sentado em seu escritório em Dehra Dun quando um computador chamado Hennessey (naquele tempo os computadores eram em carne e osso, não tinham drives de disco nem chips de silicone) entrou correndo e disparou: 'Senhor, descobri a montanha mais alta do mundo!' [Sic!]. A montanha que ele 'descobrira' se projetava da crista do Himalaia, no reino proibido do Nepal, e na época era conhecida apenas pelo algarismo romano XV. Pelos cálculos de Hennessey, erguiase à altura estonteante de 8839 metros acima do nível do mar (Krakauer, 1999, p.139).

Após a confirmação de que se tratava da montanha de maior altitude, segundo as descrições de Krakauer, o supervisor-geral mencionado decidiu "batizá-la" como Monte Everest, em homenagem a George Everest, seu antecessor no cargo. É oportuno lembrar que a referida montanha naquela ocasião já era conhecida por vários nomes, dentre os quais se destaca Chomolungma, designação atribuída pelos aldeões que moravam próximos e cujo significado é Deusa Mãe do Mundo (Krakauer, 1999, p.140).

Dessa primeira incursão, é possível recuperar uma circunstância prática na qual se possibilita visualizar claramente a forma como se constroem as lutas pelas representações, e que, bem na verdade, se tratam das próprias lutas pelas classificações e denominações em jogo. Ao nomear uma montanha já nomeada, Andrew Waugh valeu-se da posição de prestígio em que se situava, a qual, a propósito fora decisiva para fazer prevalecer a denominação por ele conferida e, consequentemente, atrair vantagens simbólicas a George Everest e, obviamente, a ele próprio.

Outro aspecto que merece destaque refere-se ao fato de que, uma vez conferida ao Everest a condição 
de montanha mais alta do mundo, estimulou-se uma corrida ao seu topo. Segundo KraKaUer (1999):

Nem é preciso dizer que, uma vez firmemente estabelecido como ponto mais alto da superfície da Terra, não demorou muito para que os homens decidissem que o Everest precisava ser escalado. Chegar ao cume, declarou G.O.Dyrenfurth, influente historiador dos primórdios do montanhismo no Himalaia, é 'uma questão de empenho humano universal, uma causa da qual não há como escapar, independentemente dos custos que o empreendimento possa acarretar' (p.140).

Depreende-se aqui uma perspectiva de busca pela distinção. $\mathrm{O}$ eventual prestígio alcançado com a chegada ao cume, bem como o domínio sobre a montanha, justificaria quaisquer esforços. Inclusive, é no impulso desses sentimentos, emoções e proezas que muitos alpinistas perderam suas vidas durante escaladas. Não obstante esse cenário de risco, a façanha de conquistar o Everest foi alcançada apenas 100 anos após a descoberta da montanha. Os responsáveis por esse feito foram o neozelandês Ed Hillary e o sherpa Tenzig Norgay.

O segundo ponto a ser aqui recuperado, diz respeito à corrida científica que se travou no sentido de descobrir outra montanha cuja altitude suplantasse a do Everest. Na esteira dessas considerações, é oportuno frisar que a consagração dos agentes envolvidos na descoberta e, posteriormente, na escalada do Everest não foi suficiente para pôr um fim à questão. Ademais, parece evidente que tal inquietação não era ingênua. Pelo contrário, o que estava em jogo era a imposição de um novo limite através de práticas que visavam ao reconhecimento e à consagração.

Nessa corrida, merece destaque os estudos envolvendo a montanha denominada Anyie Machin, situada, a saber, no território chinês. Dessa inserção acadêmica, depreende-se uma luta por representações específicas no campo científico e que, por conta dos capitais simbólicos e econômicos em jogo, fora também estendida ao subcampo do montanhismo.

Acresça-se a essa análise, o fato de que definir uma nova representação, mais apropriada cientificamente, permitiria atrair um lucro de distinção aos agentes que o fizessem. Sobre essa nova estrutura no plano das representações, vale dizer que a mesma potencialmente constituiria uma nova realidade, fundada e fundamentada numa nova visão e di-visão do espaço social. Em que pesem todos os esforços promovidos nesse sentido, no ano de 1970 a altitude do Anyie Machin foi definitivamente calculada em apenas 6282 metros, em face dos mais de oito mil do Everest.
O terceiro aspecto central destacado da narrativa evidencia uma minuciosa descrição técnica dos procedimentos utilizados para medir a altitude de uma montanha. Conforme narra KraKaUER (1999): Medir montanhas (...), é uma tarefa diabolicamente difícil, com espaço de sobra para que se cometam erros. Como explica Louis Baume em Sivalaya, um compêndio de fatos sobre as catorze maiores montanhas do mundo, 'o cálculo das altitudes dos picos do Himalaia é um campo de tanta complexidade erudita que nem mesmo anjos munidos de teodolitos e fios de prumo ousariam meter o nariz no assunto [Sic!](p.146).

O conceito bourdieusiano de capital intelectual permite um melhor entendimento das direções tomadas pelo "jogo social" retratado na fala de Krakauer, já que medir montanhas não é uma tarefa que possa ser realizada por qualquer pessoa. Bem na verdade, quem se propóe a tal empreendimento possui o mínimo de competência técnica e intelectual, dada a "complexidade erudita" exigida.

Além desses requisitos, também se reitera o fato dos agentes envolvidos no referido processo não serem destituídos de capital econômico, haja vista que os instrumentos utilizados para a aferição da altitude de uma montanha são de difícil acesso, além de muito dispendiosos.

O quarto ponto delimitado se refere à descoberta de uma montanha, denominada K2 e cuja altitude possivelmente superaria a do Everest. Os desdobramentos e implicaçôes sociais pertinentes a esse fato refletem a forma como a distinção social se vincula ao universo de disputas no subcampo esportivo em questão. Em junho de 1986, um astrônomo norte-americano chamado Wallerstein, utilizando uma nova metodologia para a realização dos cálculos, concluiu ser possível que o K2 fosse a montanha de maior altitude.

Embora o cientista tivesse alertado para o fato de que não poderia afirmar "que o K2 era mais alto do que o Everest, apenas que talvez fosse" (KraKaUER, 1999, p.147), ascendeu a uma posição de prestígio no campo científico e também nos campos correlatos. KraKAUER (1999) salienta que:

A despeito das próprias advertências de Wallerstein acerca da natureza especulativa de sua revisão para mais da altitude do K2, a notícia de que o pico poderia ser mais alto do que o Everest criou grande excitação, sobretudo na Itália. Logo depois que a notícia foi divulgada simultaneamente pela revista Outside e pelo New York Times, Wallerstein foi soterrado por uma avalanche de pedidos de entrevistas de jornais e estações de televisão 
italianas. Além dos italianos, boa parte dos montanhistas do mundo (exceção possivelmente feita àqueles que haviam escalado o Everest) torcia ferozmente pelo K2, entendendo que, sendo uma montanha mais bonita e muito mais difícil de escalar, o pico merecia ser o mais alto. Em meio a todo esse burburinho, porém, Bradford Washburn - que tivera papel fundamental na destruição da aura do Anye Machin - insistia que, quando a poeira assentasse, o Everest continuaria sendo o primeiro. E se não fosse? 'Bem', concedeu o eminente agrimensor, 'nesse caso acho que Ed Hillary pode ficar um pouco abalado' (p.149).

Evidencia-se, nessa passagem, uma estratégia de distinção social que obteve predominância no universo de disputas do subcampo do montanhismo na estrutura daquele momento. Após sua "descoberta”,
Wallerstein, de fato, ascendeu à posição de prestígio no campo científico. Em última análise, percebeu-se também uma perspectiva de apropriação daquela ostentação pela imprensa italiana, tendo em vista terem sido de nacionalidade italiana os primeiros alpinistas a conquistarem o cume da "suposta" montanha mais alta do mundo.

Após novas verificaçōes, no entanto, ficou comprovado que o Everest de fato tinha a maior altitude. Sendo assim, as disposições distintivas remeteram-se novamente às condiçôes estruturais anteriores. Por conta dessa leitura, infere-se ainda que "Hillary e Tenzing sem dúvida respiraram aliviados" (KRAKAUER, 1999, p.150), na medida em que poderiam conservar a distinção exclusiva e "póstuma" de serem os primeiros a conquistarem o "topo do mundo".

\section{Considerações para o fechamento}

No presente artigo procurou-se transitar, a partir dos pressupostos teórico-metodológicos da sociologia reflexiva de Pierre Bourdieu, pelo universo esportivo do montanhismo. Nesse percurso foram recuperados, primeiramente, os principais conceitos trabalhados pelo autor francês na teoria das representaçóes sociais e na economia dos bens simbólicos, procurando associar as últimas à lógica de distinção social explícita e manifesta no campo esportivo.

Dadas as peculiaridades do subcampo em análise, percebeu-se a pertinência dos pressupostos teóricoconceituais de Bourdieu para articular a leitura do material empírico delimitado, no qual, a saber, foi possível identificar algumas lutas por representações e seu posterior papel na construção da realidade no subcampo esportivo em questão, ao longo de aproximadamente 150 anos, segundo as impressóes temporais de Krakauer.

Nesse período relativamente amplo, um dos principais objetos de disputa em jogo, se vinculou em torno da definição e classificação da maior montanha do mundo. Por sua vez, essas definições se demonstraram associadas a posições distintivas, conferidas àqueles que conseguiram alcançar a façanha de serem os precursores, tanto no que diz respeito à descoberta científica como também à escalada propriamente dita da montanha mais alta.

Além disso, percebeu-se aqui uma ligeira circunscrição de objetivos e valores simbólicos entre os diferentes campos que, de uma forma ou outra, se apropriaram e se apropriam da prática do montanhismo, tais como, o campo científico, o jornalístico e principalmente o campo esportivo que por sinal aqui foi problematizado mais diretamente com o intuito de discutir o caráter de esportividade dessa prática.

Ainda sobre os valores e significados esportivos do montanhismo é importante reconhecer que foi justamente isso que se buscou, com seus devidos limites, recuperar nesse artigo enfatizando em tão presente medida alguns lucros de distinção inerentes à conformação do montanhismo como prática de relativa concorrência no campo esportivo e no universo dos esportes de aventura da natureza. Maiores aprofundamentos, entretanto, ficam reservados para oportunidades futuras.

Por fim, convém frisar que o esforço intelectual suscitado na construção do presente artigo se desdobrou no sentido de recuperar e ainda sistematizar, no interior de um quadro de análise bem específico, alguns dos pressupostos teórico-metodológicos bourdieusianos indispensáveis e norteadores para constituição de um referencial compatível para leitura sociológica dos esportes em contato com a natureza, no caso particular desse texto, uma leitura sociológica dos contornos conferidos pelas representações sociais à construção de uma realidade objetivada e objetivante no subcampo esportivo do montanhismo. 


\begin{abstract}
Social representations and reality's institucion on sporting subfield of mountaineering: a possibility of sociologic reading from the composition "Sobre homens e montanhas" by Jon Krakauer

The objectives in which the construction of the present article were based lead, from a side, to identify some social representations present in the mountaineering universe and, on the other, to understand the form like the same representations, in the struggle and the competition contribute to the construction of social reality in this delimited empirical universe. For the development of this proposal it was sough metodological support in the reflexive sociology of Pierre Bourdieu, especially in his acquired and explicated form in the construction of the social representations theory, of the economy of the symbolic goods and of the profits of distinction in the sporting field. Finally, it was still nourished in the empirical considerations woven by the mountaineer and writer Jon Krakauer in his best seller "On men and mountains".
\end{abstract}

UNITERMS: Social representations; Mountaineering; Sociology; Pierre Bourdieu.

\title{
Referências
}

BOURDIEU, P. A metamorfose dos gostos. In: Questóes de sociologia. Rio de Janeiro: Marco Zero, 1983a. p.127-35. Como é possível ser esportivo? In: Questóes de sociologia. Rio de Janeiro: Marco Zero, 1983b. p.136-53. Programa para uma sociologia do esporte. In: Coisas ditas. São Paulo: Brasiliense, 1990. p.207-20.

A economia das trocas linguiísticas. São Paulo: EDUSP, 1998.

A distinção: crítica social do julgamento. São Paulo: EDUSP; Porto Alegre: Zouk, 2007a.

Razóes práticas: sobre a teoria da ação. 8. ed. Campinas: Papirus, 2007b.

CHARTIER, R. À beira da falésia: a história entre incertezas e inquietudes. Porto Alegre: Ed. Universidade/UFRGS, 2002. DURKHEIM, E. As formas elementares da vida religiosa: o sistema totêmico na Austrália. São Paulo: Martins Fontes, 1996.

KRAKAUER, J. Sobre homens e montanhas. São Paulo: Companhia das Letras, 1999.

ENDEREÇO

J uliano de Souza

R. J osé Zagonel Passos, 460

85027-110 - Guarapuava - PR - BRASIL e-mail: julianoedf@yahoo.com.br
Recebido para publicação: 05/ 11/ 2009

Revisado: 03/05/2011

Aceito: 30/05/2011 